\title{
ANTEMORTEM DIAGNOSIS AND SURGICAL \\ MANAGEMENT OF SPLENITIS DUE TO \\ YERSINIA PSEUDOTUBERCULOSIS INFECTION \\ IN A PET RABBIT (ORYCTOLAGUS CUNICULUS)
}

\author{
Lucile Chassang, DVM, IPSAV, Graham Zoller, DVM, IPSAV, Pauline Loos, DVM, IPSAV ${ }^{1}$, \\ Eymeric Gomes, DVM, DECVDI, Camille Bismuth, DVM, DECVS, \\ Alexandra Briend-Marchal, DVM, DECVCP, Alexandra Nicolier, DVM, DECVP, and \\ Minh Huynh, DVM, DECZM (Avian)
}

\begin{abstract}
A 6.5-year-old pet rabbit (Oryctolagus cuniculus) was presented for severe weakness, dysorexia, and weight loss. The rabbit had been treated for diarrhea and anorexia 3 weeks before. Pale mucous membranes and a 2-cm abdominal mass cranial to the caecum were noted on clinical examination. Blood tests revealed a severe nonregenerative anemia with neutrophilia and thrombocytosis suggestive of an ongoing inflammatory process, and an elevation of liver enzymes. Abdominal ultrasonography showed an enlarged heterogenous spleen and mild abdominal effusion. Initial stabilization required intravenous fluid therapy and a blood transfusion, associated with broad spectrum antibiotics and analgesia. An exploratory laparotomy was performed and revealed whitish disseminated lesions in the splenic parenchyma. Splenectomy was performed during the exploratory laparotomy using a vessel sealing device and a second blood transfusion was administered. Bacterial culture, cytology, and histopathological examination were diagnostic of a yersiniosis due to Yersinia pseudotuberculosis, with a severe splenitis and a mild hepatitis. Postoperative care included supportive care, analgesia, and antibiotics. Clinical signs resolved after 6 days of hospitalization. The rabbit died 20 months later from an unrelated condition. Copyright 2018 Elsevier Inc. All rights reserved.
\end{abstract}

Key words: rabbit; splenitis; yersinia pseudotuberculosis; intensive care; splenectomy

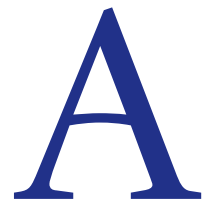

6.5-year-old, 1.65-kg neutered female pet rabbit (Oryctolagus cuniculus) was presented with a 4-day history of lethargy, weakness, and reduced appetite. Three weeks before, the rabbit had been hospitalized for an episode of lethargy, anorexia, and diarrhea. At this time, blood chemistry results were within normal ranges, and a typhlitis was suspected based on abdominal ultrasonography findings. Treatments included subcutaneous crystalloid fluids (25 mL/kg, every 6 hours), metronidazole $(20 \mathrm{mg} / \mathrm{kg}$, orally, twice daily; Flagyl $125 \mathrm{mg} / 5 \mathrm{~mL}$, SanofiAventis, Paris, France), buprenorphine $(0.03 \mathrm{mg} / \mathrm{kg}$, subcutaneously, every 6 hours; Vetergesic, Ceva Santé Animale, Libourne, France), trimebutine $(1.5 \mathrm{mg} / \mathrm{kg}$, orally, twice daily; Débridat, Pfizer Holding France, Paris, France) and syringe feedings $(20 \mathrm{~mL} / \mathrm{kg}$, orally, every 6 hours; Oxbow Critical Care, Oxbow Animal Health, Murdoch, NE, USA). The rabbit was discharged after 2 days of hospitalization with metronidazole and trimebutine for 3 weeks. The rabbit continued to improve at home and its appetite was normal when the medication was stopped. Two days after discontinuation, the rabbit's condition deteriorated and it rapidly became hyporexic and weak with difficulty standing.

\footnotetext{
Abbreviations: ALT, alanine aminotransferase; PCV, packed cell volume

From the Exotics Department, CHV Frégis, Arcueil, France; the Small Animal Department, CHV Frégis, Arcueil, France; the Laboratoire Vebio, Arcueil, France; and the Vet Diagnostics, Lyon, France

Address correspondence to: Lucile Chassang, DVM, IPSAV, Exotics Department, CHV Frégis, 43 avenue Aristide Briand, 94110 Arcueil, France.E-mail: chassang.lucile@gmail.com

${ }^{1}$ Present address: Laboratory of Immunology-Vaccinology, Department of Infectious and Parasitic Diseases, Faculty of Veterinary Medicine, University of Liège, Liège, Belgique.

(C) 2018 Elsevier Inc. All rights reserved. $1557-5063 / 14 / 2101-\$ 30.00$

https://doi.org/10.1053/j.jepm.2018.05.006
} 
On physical examination, rectal temperature was $39.3^{\circ} \mathrm{C}$ (reference range: $38^{\circ} \mathrm{C}$ to $40^{\circ} \mathrm{C}$ ), ${ }^{1}$ which was considered high as the rabbit was very lethargic. Mucous membranes were pale and capillary refill time was not evaluable. Moderate tachypnea (130 mpm; reference range: 32 to 60 mpm $)^{2}$ was noted. Cardiothoracic auscultation revealed a systolic left apical heart murmur (grade II/VI). A 2-cm firm irregular mass was identified in the medium left abdomen, just cranially to the caecum. The rabbit showed no abdominal pain.

A complete blood count revealed a severe nonregenerative anemia with a packed cell volume (PCV) of $13 \%$ (reference range: $33 \%$ to $50 \%$; $^{3}$ Table 1 ). In addition, a heterophilic and monocytic leukocytosis as well as a thrombocytosis were noted (Table 1). Blood biochemistry showed moderately increased ALT activity (236 U/L; reference range: 25 to $65 \mathrm{U} / \mathrm{L}),{ }^{4}$ consistent with liver damage. Thoracic survey radiographs were unremarkable. Abdominal ultrasonography revealed a marked splenomegaly with a heterogeneous hypoechoic parenchyma and a highly vascularized area (Fig. 1). A moderate amount of anechoic peritoneal effusion was also noted.

Initial therapy included intravenous fluid therapy (lactated ringer, $5 \mathrm{~mL} / \mathrm{kg} / \mathrm{h}$; B.Braun Medical France, Boulogne-Billancourt, France), trimethoprim sulfamethoxazole $(30 \mathrm{mg} / \mathrm{kg}$, orally, twice daily; Bactrim, Roche, Boulogne-Billancourt),

TABLE 1. Hematology results of a 6.5-year-old pet rabbit with a history of weakness and anorexia at the time of hospital admission

\begin{tabular}{lll} 
& Patient & Reference range \\
\hline $\begin{array}{l}\text { Packed cell volume (\%) } \\
\text { Hemoglobin }(\mathrm{g} / \mathrm{dL})\end{array}$ & 13 & 33 to 50 \\
$\begin{array}{c}\text { Red blood cells } \\
\left(\times 10^{12} \text { cells/L) }\right.\end{array}$ & 1.8 & 11.5 to 15.1 \\
$\begin{array}{c}\text { White blood cells } \\
\quad \times 10^{9} \text { cells/L) }\end{array}$ & 11.5 & 6.30 to 10.06 \\
$\begin{array}{c}\text { Heterophils } \\
\left(\times 10^{9} \text { cells/L) }\right.\end{array}$ & 6.79 & 1.49 to 3.21 \\
$\begin{array}{c}\text { Lymphocytes } \\
(\times 109 \text { cells/L) }\end{array}$ & 3.68 & 3.36 to 7.00 \\
$\begin{array}{c}\text { Ratio heterophils: } \\
\text { lymphocytes }\end{array}$ & 1.8 & $>1$ \\
$\begin{array}{c}\text { Monocytes } \\
(\times 109 \text { cells/L) }\end{array}$ & 1.04 & 0.05 to 0.45 \\
$\begin{array}{c}\text { Eosinophils } \\
(\times 109 \text { cells/L) }\end{array}$ & 0 & 0.01 to 0.15 \\
$\begin{array}{c}\text { Basophils } \\
(\times 109 \text { cells/L) }\end{array}$ & 0 & 0.06 to 0.36 \\
$\begin{array}{c}\text { Thrombocytes } \\
(\times 109 \text { cells/L) }\end{array}$ & 799 & 250 to 610 \\
\hline
\end{tabular}

buprenorphine ( $0.03 \mathrm{mg} / \mathrm{kg}$, every 6 hours), and syringe feeding ( $20 \mathrm{~mL} / \mathrm{kg}$, orally, every 6 hours). Six hours after hospital admission, the rabbit's condition deteriorated. Therefore, a whole blood transfusion was performed. ${ }^{5}$ The donor's PCV was within normal ranges (42\%) and major crossmatch was negative. Fifteen milliliters of blood were drawn in a syringe prepared with a citrate-phosphate-dextrose-adenine solution in a ratio of 1:9 mL of blood (CPDA 135 $\mathrm{mL} / 250 \mathrm{~mL}$, Macopharma, Mouvaux, France). The transfusion was administered over 3 hours at $5 \mathrm{~mL} /$ $\mathrm{kg} / \mathrm{h}$ with close monitoring. No adverse reaction was observed. Post-transfusion PCV was 24\% and the rabbit's general condition had significantly improved.

On day 2, the rabbit was scheduled for an exploratory laparotomy. The rabbit was premedicated with ketamine $(5 \mathrm{mg} / \mathrm{kg}$, intramuscularly; Ketamine 1000, Virbac France, Carros, France), midazolam $(0.5 \mathrm{mg} / \mathrm{kg}$, intramuscularly; Midazolam Sandoz, Sandoz, Levallois-Perret, France), and morphine (1 mg/kg, subcutaneously; Morphine Lavoisier $10 \mathrm{mg} / \mathrm{mL}$, Laboratoire Chaix et du Marais, Paris, France). Anesthesia was induced with propofol ( $4 \mathrm{mg} / \mathrm{kg}$ intravenously; Propofol Fresenius, Fresenius Kabi France, Sèvres, France) and ketamine ( $5 \mathrm{mg} / \mathrm{kg}$ intravenously) administered to effect and the rabbit was intubated using a 3.0-mm endotracheal tube. Anesthesia was maintained with isoflurane in 100\% oxygen. A 20-mL whole blood transfusion was administered over 4 hours at $5 \mathrm{~mL} / \mathrm{kg} / \mathrm{h}$, intra- and postoperatively. A routine ventral midline laparotomy was performed. Abdominal exploration revealed a severely enlarged and heterogeneous spleen with whitish lesions (Fig. 2-A), a discretely heterogeneous liver and a moderate serosanguinous effusion. A splenectomy was performed using a vessel sealing device (LigaSureTM small jaw instrument, Covidien, Elancourt, France; Fig. 2-B). A liver biopsy was taken using the same device. Samples were submitted for cytological examination, aerobic bacterial culture, and histopathological examination. The abdomen was lavaged with warm saline and routinely closed. Immediate postoperative care included oxygen supplementation, continuous intravenous analgesia combining fentanyl $(1.25 \mu \mathrm{g} / \mathrm{kg} / \mathrm{h}$; Fentanyl Renaudin $500 \mu \mathrm{g} / 10 \mathrm{~mL}$, Laboratoire Renaudin, Cambo les Bains, France), lidocaine ( $1 \mathrm{mg} / \mathrm{kg} / \mathrm{h}$; Xylocaine 2\%, Astrazeneca, Rueil Malmaison, France) and ketamine $(0.12 \mathrm{mg} / \mathrm{kg} / \mathrm{h})$, fluid therapy (lactated ringer, $10 \mathrm{~mL} / \mathrm{kg} / \mathrm{h}$, intravenous), meloxicam (1 mg/kg, subcutaneously, twice daily; Metacam, Boehringer Ingelheim, Ingelheim/Rhein, Germany), trimethoprim sulfamethoxazole 


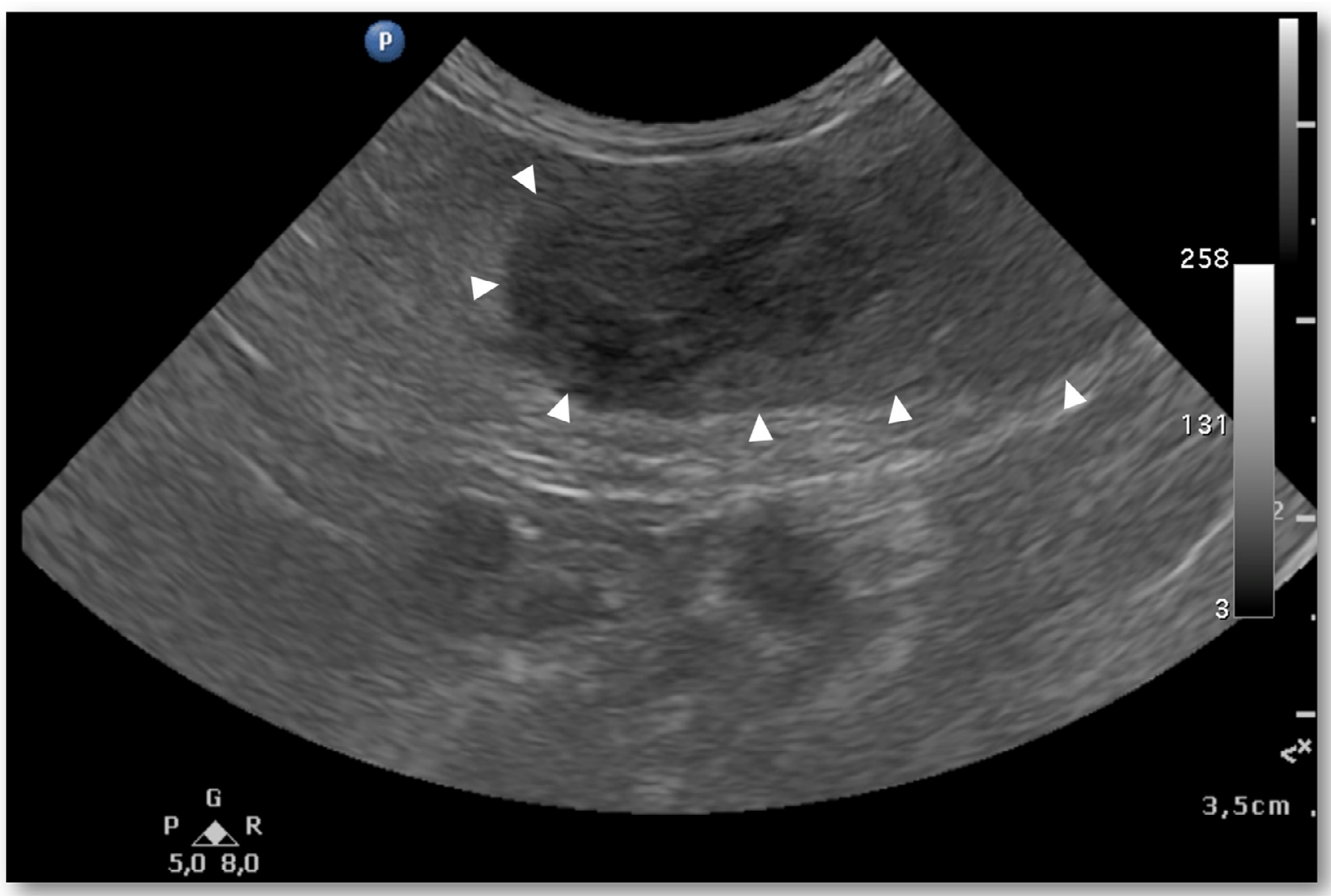

FIGURE 1. B-mode abdominal ultrasonographic image of a 6.5-year-old pet rabbit with a history of weakness, anorexia, and anemia. Splenomegaly with heterogenous parenchyma is noted (white arrowheads). The scale on the right side of the image indicates measurement in centimeters.

(30 mg/ $\mathrm{kg}$, orally, twice daily), and syringe feeding (15 mL/kg, orally, every 4 hours). After the second blood transfusion, PCV reached a value of $30 \%$.

On day 3, the rabbit was still lethargic, anorectic, and tachypneic. Rectal temperature was persistently within the high values of the normal range $\left(39.2^{\circ} \mathrm{C}\right.$ to $39.5^{\circ} \mathrm{C}$ ). Spleen cytology revealed a lymphoid hyperplasia associated with a moderate nonspecific inflammatory infiltrate. The effusion was characterized as pyo-granulomatous. Based on these results, an infectious etiology was strongly suspected. Given the absence of improvement of the rabbit's condition with the current antimicrobial treatment, antibiotherapy was modified for intravenous metronidazole $(20 \mathrm{mg} / \mathrm{kg}$, twice daily; Flagyl 0.5\%, Sanofi-Aventis, Gentilly, France) and marbofloxacin (5 mg/kg, twice daily; Marbocyl FD, Vetoquinol, Lure, France).

On day 4 , rectal temperature decreased $\left(37.5^{\circ} \mathrm{C}\right.$ to $38.5^{\circ} \mathrm{C}$ ) and respiratory rate slowed down significantly ( 80 to $84 \mathrm{mpm}$ ). The rabbit's condition gradually improved and analgesic coverage was progressively decreased. Constant rate infusion of analgesic was replaced by morphine ( $1 \mathrm{mg} / \mathrm{kg}$, subcutaneously, every 4 hours).
On day 6, blood biochemistry revealed a persistent elevation of ALT activity (195 U/L) and PCV value was stable (29\%). Bacterial culture yielded pure growth of Yersinia pseudotuberculosis, with antimicrobial sensitivity to most antibiotics, including marbofloxacin and trimethoprim sulfamides. Morphine was switched to buprenorphine $(0.03 \mathrm{mg} / \mathrm{kg}$, subcutaneously, every 6 hours) and fluid therapy was continued with subcutaneous administration $(20 \mathrm{~mL} / \mathrm{kg}$, every 6 hours) based on adequate appetite and fecal production. Metronidazole was given orally and marbofloxacin was administered subcutaneously, at the same dosages.

The rabbit was discharged on day 7 . Oral marbofloxacin and metronidazole were prescribed. The other rabbit of the household was preventively treated with trimethoprim sulfamethoxazole for 7 days.

On histopathological examination, the splenic parenchyma was severely modified by large multifocal to coalescent areas of necrosis with accumulation of cellular debris, fibrin, live and degenerated heterophilic granulocytes, and rare macrophages and lymphocytes (Fig. 3). Large 
A

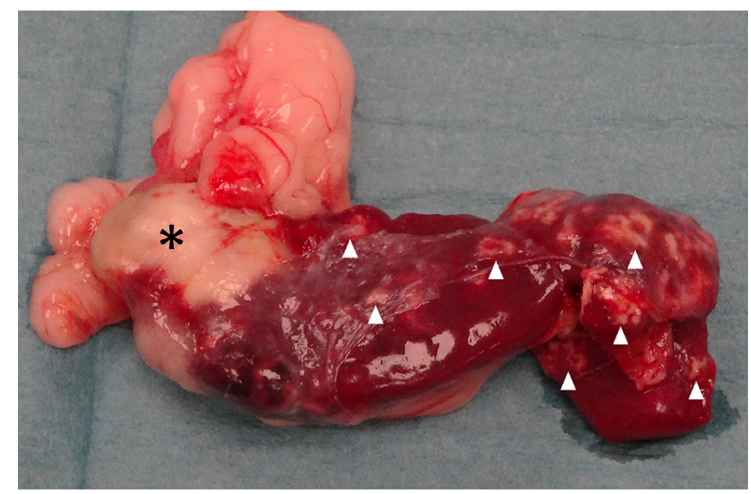

B

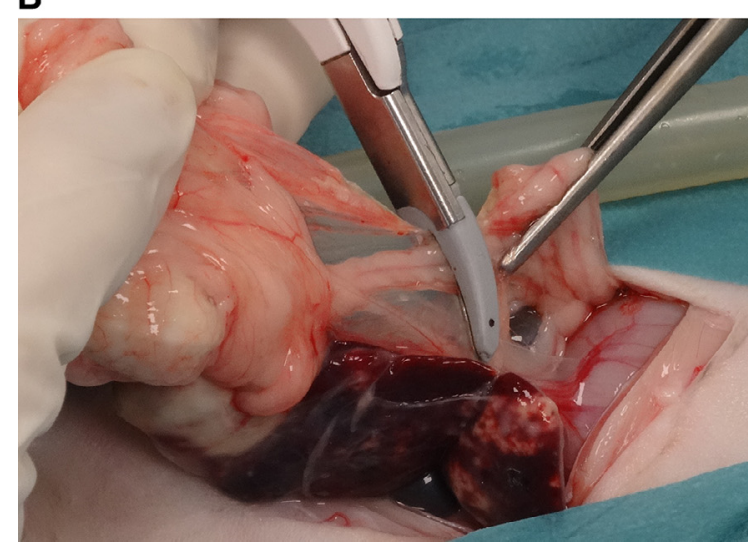

FIGURE 2. Photographs obtained during the exploratory laparotomy and splenectomy of a 6.5-yearold pet rabbit. (A) A 2-cm white nodule is noted at the tail of the spleen (black asterisk). The spleen appears severely enlarged with whitish lesions disseminated in the parenchyma (white arrowheads). (B) During splenectomy, a vessel sealing device was used to obtain hemostasis of the splenic branches.

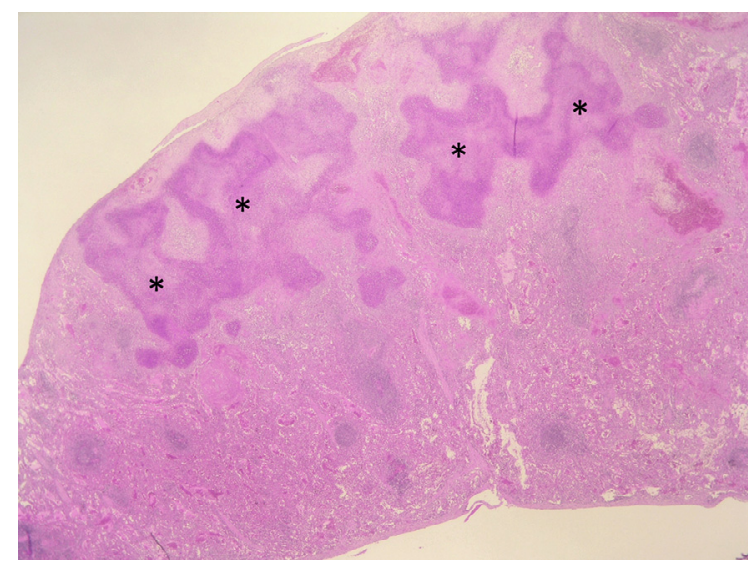

FIGURE 3. Photomicrograph of a section of the spleen removed from a 6.5-year-old domestic rabbit showing large coalescing areas of necrosis (black asterisks). Hematoxylin-eosin X 2.

colonies of basophilic coccobacilli were observed in the center of the necrotic areas. These findings were consistent with a severe multifocal acute fibrino-necrotizing splenitis with intralesional coccobacilli, suggestive of a yersiniosis. A mild multifocal acute necrotizing and heterophilic hepatitis was also identified. Based on bacteriological and histopathological findings, a diagnosis of splenitis and hepatitis due to $Y$. pseudotuberculosis infection was made.

A week after discharge, physical examination revealed no significant abnormality. PCV was within normal ranges (44\%) as well as ALT activity (41 U/L). Antibiotherapy was continued for another 2 weeks.

Four months after surgery, a complete blood count, a blood biochemistry, and an ultrasonography were within normal limits. The rabbit died 20 months after surgery from an unrelated condition.

\section{DISCUSSION}

Pseudotuberculosis, is an uncommon zoonotic infectious disease of domestic pets, but is considered as the most important cause of clinical disease in captive wildlife. ${ }^{6}$ The disease has been reported in a wide range of species and is commonly encountered in free-range lagomorphs. ${ }^{7,8}$ Y. pseudotuberculosis is a gramnegative, aerobic coccobacillus that belongs to the family Enterobacteriaceae. ${ }^{6,9}$ It is distributed globally but is particularly prevalent in Europe. Transmission mainly occurs through ingestion of foodstuff contaminated by feces of wild birds and rodents. ${ }^{6}$ In this case, the rabbit used to eat the leftover seeds from wild birds fed in the owners' garden, which was the suspected source of contamination.

In rabbits, limited data are available regarding the clinical course of the disease. The bacterium seems to penetrate mainly through the epithelium of the duodenum and jejunum after oral contamination. ${ }^{10}$ In most species, yersiniosis is not characterized by any specific clinical signs. In experimental studies, rabbits exhibit signs of depression and isolation 5 to 7 days postinfection. ${ }^{11,12}$ Longer incubation times of 15 days or more are suggested by some authors. ${ }^{13}$ Rabbits also display weight loss, ruffled fur, and increase in body temperature between $39.2^{\circ} \mathrm{C}$ and $39.7^{\circ} \mathrm{C} .{ }^{11,12}$ Pneumonia, enteritis with diarrhea, and palpable nodules on the liver have also been reported. ${ }^{13}$

In veterinary medicine, ante-mortem diagnosis of pseudotuberculosis has only been reported in a $\mathrm{cat}^{14}$ and was obtained by exploratory laparotomy with biopsies for histopathological examination and bacterial culture. In human medicine, 
Y. pseudotuberculosis infection commonly causes an acute appendicitis-like syndrome. ${ }^{15}$ Diagnostic imaging such as ultrasonography or computed tomography is generally required to differentiate this disease from appendicitis, fecal culture or PCR have been used to diagnose the disease in humans. ${ }^{15-17}$ However several cases from recent publications needed exploratory laparotomy or laparoscopy to remove infected tissues or collect biopsies for definitive diagnosis with histopathological examination or bacterial culture. ${ }^{18-20}$ In our case, the main site of infection was the spleen. Ultrasonographic diagnosis of splenic lesions is uncommon in rabbits and has mostly been described in experimental Epstein-Barr virus infections. ${ }^{21}$ Bacterial culture of samples taken during exploratory laparotomy was needed to get a definitive diagnosis in our patient. Ultrasound-guided fine needle aspiration of abdominal effusion or spleen could have enabled an early diagnosis but none was safely accessible. Furthermore, the caecum is the primary colonization site and it appears to serve as a reservoir for dissemination of the infection to extraintestinal sites in mice. ${ }^{22}$ Typhlitis may have been the first sign of the disease in this case and a fecal culture might have enabled an even earlier diagnosis.

Treatment of the disease in rabbits has never been reported ${ }^{13}$ but enteropathogenic Yersinia species are usually susceptible to doxycycline, trimethoprim-sulfamethoxazole, chloramphenicol, aminoglycosides, and fluoroquinolones. ${ }^{9}$ In addition to antibiotherapy, this rabbit's treatment included blood transfusions and splenectomy. Transfusion has rarely been reported in pet rabbit medicine. It is assumed that rabbits with a PCV of $15 \%$ or less may benefit from red blood cell transfusion. ${ }^{23}$ In this case, the rabbit's PCV was $13 \%$ and significant clinical improvement was achieved with the transfusions. Transfusion reactions are considered hypothetical ${ }^{23}$ and none was observed in this case, although a second donor was used.

Splenectomy is frequently performed in ferrets and dogs, and less frequently in cats. In rabbits, the surgical technique is similar to small animals ${ }^{24}$ except for anatomical variations. The rabbit's spleen is flat and elongated with a longitudinal hilus running along its visceral surface, located on the left caudolateral aspect of the stomach. The splenic artery arises from the celiac artery and proceeds toward the splenic hilus. It runs along the hilus, giving several splenic branches supplying the spleen and continues as the left gastroepiploic artery toward the great curvature of the stomach.
Splenic branches often arise as trunks in common with short gastric arteries. ${ }^{25} \mathrm{~A}$ vessel sealing device was used in this rabbit, such as reported in dogs. ${ }^{26}$ It is a safe tool for performing splenectomy in dogs, and enables a good hemostasis for vessels up to 7 mm diameter, with minimal to no need of surgical dissection before application and no remaining foreign material. This technique was used successfully in this rabbit and no long-term postoperative complication has been noted.

Splenectomy has been commonly performed in laboratory rabbits to study its consequences on the immune system. Spleen is the major site of antibody forming cells that subsequently migrates to the lymph nodes and thymus in splenectomized rabbits. ${ }^{27}$ Splenectomized rabbits are capable of mounting a satisfactory immune response. Splenectomy is however associated with a lower resistance to septicemia. ${ }^{28-30}$ Before performing splenectomy in rabbits, higher sensitivity to bacterial infections need to be considered as an expected long-term complication and close monitoring of splenectomized rabbits is advocated.

To the authors' knowledge, this is the first report of antemortem diagnosis and management of a splenitis due to $Y$. pseudotuberculosis in a pet rabbit in the veterinary literature. Findings in the rabbit of this report suggest that $Y$. pseudotuberculosis may be suspected in rabbits exhibiting diarrhea, weight loss, and anemia with an inflammatory leukogram. Also, splenectomy using a vessel sealing device provided a safe alternative surgical technique in this patient.

\section{REFERENCES}

1. Di Girolamo N, Toth G, Selleri P: Prognostic value of rectal temperature at hospital admission in client-owned rabbits. J Am Vet Med Assoc 248:288-297, 2016

2. Varga M: Chapter 1-rabbit basic science, in Varga M (ed): Textbook of Rabbit Medicine, (ed 2). Edinburgh, UK, Butterworth-Heinemann, pp 3-108, 2014

3. Campbell TW: Appendix B-hematologic values, in Campbell TW (ed): Exotic Animal Hematology and Cytology, (ed 4). Ames, Iowa, USA, Wiley Blackwell, pp 383-391, 2015

4. Varga M: Chapter 2-clinical pathology, in Varga M (ed): Textbook of Rabbit Medicine, (ed 2). Edinburgh, UK, Butterworth-Heinemann, pp 111-136, 2014

5. Lichtenberger M: Transfusion medicine in exotic pets. Clin Tech Small Anim Pract 19:88-95, 2004

6. Alchurch AF: Yersiniosis in all taxa, in Fowler ME (ed): Zoo and Wild Animal Medicine, (ed 5). St. Louis, MO, USA, Elsevier Science, pp 724-727, 2003

7. Wobeser G, Campbell GD, Dallaire A, et al: Tularemia, plague, yersiniosis, and Tyzzer's disease in wild rodents and lagomorphs in Canada: A review. Can Vet J 50: 1251-1256, 2009 
8. Nikolova S, Tzvetkov Y, Najdenski H, et al: Isolation of pathogenic yersiniae from wild animals in Bulgaria. J Vet Med B Infect Dis Vet Public Health 48:203-209, 2001

9. Sykes JE, Chomel BB: Chapter 55 - Yersinia pestis (Plague) and Other Yersinioses, in Sykes JE (ed): Canine and Feline Infectious Diseases, St. Louis, MO, USA, W.B. Saunders, pp 531-536, 2014

10. Isachkova LM, Zhavoronkov AA, Timchenko NF: Interaction of Yersinia pseudotuberculosis with the epithelium of the small intestine in experimental infection. Biulleten Eksp Biol Meditsiny 100:117-120, 1985

11. Najdenski H, Vesselinova A, Golkocheva E, et al: Experimental infections with wild and mutant Yersinia pseudotuberculosis strains in rabbits. J Vet Med B Infect Dis Vet Public Health 50:280-288, 2003

12. Okwori AEJ, Agina SE, Odugbo MO, et al: Experimental Yersinia pseudotuberculosis enteritis in laboratory animals. Afr J Biotechnol 6:2411-2414, 2007

13. Varga M: Chapter 14 - infectious diseases of domestic rabbits, in Varga M (ed): Textbook of Rabbit Medicine, (ed 2)., Edinburgh, UK, Butterworth-Heinemann, pp 435-471, 2014

14. Spearman JG, Hunt P, Nayar PS: Yersinia pseudotuberculosis infection in a cat. Can Vet J 20:361-364, 1979

15. Lai C-H, Lin J-N, Chen Y-H, et al: The first imported human case of Yersinia pseudotuberculosis serotype O1 septicemia presents with acute appendicitis-like syndrome in Taiwan. J Formos Med Assoc Taiwan Yi Zhi 113:656-659, 2014

16. Imataki $\mathrm{O}$, Uemura $\mathrm{M}$, Matsumoto $\mathrm{K}$, et al: Yersinia pseudotuberculosis enterocolitis mimicking enteropathic $\gamma \delta$ T-cell lymphoma with abnormal clonality. BMC Infect Dis 14:42, 2014

17. Wunderink HF, Oostvogel PM, Frénay IHME, et al: Difficulties in diagnosing terminal ileitis due to Yersinia pseudotuberculosis. Eur J Clin Microbiol Infect Dis Off Publ Eur Soc Clin Microbiol 33:197-200, 2014

18. Bertelli L, Masetti R, Bardasi G, et al: Two cases of abdominal pain in children with mesenteric lymphadenitis due to Yersinia pseudotuberculosis infection. J Pediatr 65. 411-411e1

19. Kimura J, Sasaki K: Yersinia pseudotuberculosis infection intractable by antibiotics: a rare case report. Int J Surg Case Rep 21:139-141, 2016
20. Srinivasa KG, Vidhya JV, Manohar TM, et al: Right hemicolectomy for intestinal obstruction due to yersinia pseudotuberculosis: a histopathological surprise. Indian J Surg 75:214-216, 2013

21. Kanai K, Takashima K, Okuno K, et al: Lifelong persistent EBV infection of rabbits with EBER1-positive lymphocyte infiltration and mild sublethal hemophagocytosis. Virus Res 153:172-178, 2010

22. Fahlgren A, Avican K, Westermark L, et al: Colonization of cecum is important for development of persistent infection by Yersinia pseudotuberculosis. Infect Immun 82: 3471-3482, 2014

23. Huynh M, Boyeaux A, Pignon C: Assessment and care of the critically Ill rabbit. Veterinary Clin N Am Exot Anim Pract 19:379-409, 2016

24. Small Animal Surgery Textbook, in Fossum TW (ed): Small Animal Surgery Textbook, (ed 4). St. Louis, MO, USA, Elsevier Health Sciences,

25. Ikegami R, Tanimoto $\mathrm{Y}$, Kishimoto $\mathrm{M}$, et al: Anatomical variation of arterial supply to the rabbit spleen. J Vet Med Sci 78:199-202, 2016

26. Rivier P, Monnet E: Use of a vessel sealant device for splenectomy in dogs. Vet Surg VS 40:102-105, 2011

27. Barron PT, Richter M: Immunodeficiency following splenectomy in the early postimmunization period. Br J Surg 77:316-319, 1990

28. Melissas J, Wasas A, Wadee AA, et al: [Pneumococcusinduced septicemia in normal and splenectomized rabbits]. Langenbecks Arch Für Chir 377:341-344, 1992

29. Cheslyn-Curtis S, Aldridge MC, Biglin JE, et al: Effect of splenectomy on gram-negative bacterial clearance in the presence and absence of sepsis. Br J Surg 75:177-180, 1988

30. Thalhamer J, Pimpl W, Pattermann M: The role of the spleen and splenic autotransplants in clearing experimental bacteremia caused by the gram-negative bacterium Escherichia coli. Res Exp Med 186:229-238, 1986

31. Campbell TW: Chapter 1 - peripheral blood of mammals, in Campbell TW (ed): Exotic Animal Hematology and Cytology, (ed 4). Ames, Iowa, USA, Wiley Blackwell, pp 3-36, 2015 